\title{
Early prevention of trauma-related infection/sepsis
}

\author{
Xiao-Yuan $\mathrm{Ma}^{\dagger},{\text { Li-Xing } \operatorname{Tian}^{\dagger} \text { and Hua-Ping Liang }}^{*}$
}

\begin{abstract}
Trauma still represents one of the major causes of death worldwide. Despite the reduction of post-traumatic sepsis over the past two decades, the mortality of septic trauma inpatients is still high (19.5-23\%). Early prevention of sepsis development can aid in the subsequent treatment of patients and help improve their outcomes. To date, the prevention of trauma-related infection/sepsis has mainly included infection prevention (e.g., surgical management, prophylactic antibiotics, tetanus vaccination, immunomodulatory interventions) and organ dysfunction prevention (e.g., pharmaceuticals, temporary intravascular shunts, lung-protective strategies, enteral immunonutrition, acupuncture). Overall, more efficient ways should be developed to prevent trauma-related infection/sepsis.
\end{abstract}

Keywords: Prevention, Trauma, Infection, Sepsis

\section{Background}

The mortality rate of trauma is still very high and is increasing, according to the World Health Organization. It is predicted that post-traumatic mortality will be a major cause of death in 2020. Traffic injuries commonly seen in civilian trauma patients are the leading cause of prehospital death $[1,2]$. Combat-related injuries, which are a special form of trauma, will also have higher mortality rates if the wounded do not receive timely battlefield surgery and subsequent treatments [3]. Both pro- and anti-inflammatory responses are involved in the posttraumatic pathologic process, and they increase the risk of acute respiratory distress syndrome (ARDS), sepsis, and multiple organ failure (MOF). Early prevention of the development of sepsis following trauma can reduce the risk of both sepsis and multiple organ dysfunction syndrome (MODS) and can improve the patients' outcomes.

The greatest danger after hemorrhage in both civilian and combat-related injuries is sepsis. Sepsis 3.0 was put forward by Professor Craig Coopersmith, chairman of the Society of Critical Care Medicine, at the Chinese Medical Association (CMA) ninth intensive medical conference in 2015. The experts suggested that the new

\footnotetext{
* Correspondence: 13638356728@163.com

${ }^{\dagger}$ Equal contributors

State Key Laboratory of Trauma, Burns and Combined Injury, Research Institute of Surgery, Daping Hospital, Third Military Medical University, Chongqing 400042, China
}

(c) The Author(s). 2016 Open Access This article is distributed under the terms of the Creative Commons Attribution 4.0 International License (http://creativecommons.org/licenses/by/4.0/), which permits unrestricted use, distribution, and reproduction in any medium, provided you give appropriate credit to the original author(s) and the source, provide a link to the Creative Commons license, and indicate if changes were made. The Creative Commons Public Domain Dedication waiver (http://creativecommons.org/publicdomain/zero/1.0/) applies to the data made available in this article, unless otherwise stated.

\section{Infection prevention}

Preventing infection following trauma basically involves preventing wound and nosocomial infection. Wound care methods commonly include surgical management (e.g., disinfection, debridement, profuse irrigation and wound cleansing, negative-pressure wound therapy, wound drainage, appropriate wound closure) and the administration of pharmaceuticals (e.g., prophylactic antibiotics, tetanus vaccination, immunomodulatory interventions). The prevention of nosocomial infection is another aspect of infection prevention. Immune dysregulation is a well-described consequence of trauma and can increase the risk of nosocomial infection. Regional proper clinical protocols and hygiene are the correct methods according to the accepted prevention principles and include the following measures: chlorhexidine, hydrocortisone, detrusor botulinum toxin A injection, 
enteral nutrition and management of tube system, which are used to prevent ventilator associated pneumonia (VAP), central line-associated bloodstream infection and urinary tract infection (UTI).

\section{Surgical management}

\section{Hair removal and skin disinfection}

Hair is an autologous source of wound contamination, and removing hair from a wound can avoid its entanglement during suture and closure [4]. The type and time of shaving have been shown to be necessary in reducing the chance of infection. The infection rate of surgical wounds after preparing the skin with electric clippers is markedly lower than it is after preparing the skin with a razor [5]. Moreover, shaving the hair before wound repair is associated with a higher risk of surgical site infection than is clipping the hair immediately [6]. Although the use of antiseptic agents containing iodophor or chlorhexidine can suppress a broad spectrum of organisms and bacterial proliferation, they may damage wound defenses and promote the development of infection [7]. Consequently, the reasonable application of antiseptic agents to the wound should be considered.

\section{Debridement}

Wound debridement is the most common surgery used in both conflict and civilian cases. The first surgical treatment in war surgery at the first echelon hospital is debridement without primary closure [3]. The US military recommends repeat debridement and irrigation every 24-48 h before wound cleaning [8]. Debridement can remove devitalized and severely contaminated tissues and can prevent infection, and the basic principles of wound debridement are well accepted in the field of surgical management [9, 10]. However, Edlich et al. [4] suggested that less tissue debridement had been associated with a lower rate of wound infection. Thus, it is important to identify the definite limits of dead tissue, similar to the " $4 \mathrm{C}$ " guidelines (color, consistency, contraction, circulation) of muscle viability. In the case of complex traumatic hand injuries, meticulous initial debridement of nonviable tissue and skeletal stabilization are paramount in preventing hand infection [11]. Multiple debridements will be necessary if significant contamination is present.

\section{Mechanical cleansing}

Early and thorough irrigation following wound debridement is one of the important steps in the basic principles of the management of war wounds [3, 8]. Gentle irrigation with low pressure and normal saline will wash out any residual debris and clot and dilute any bacterial load, whereas high-pressure irrigation (7 psi, pounds per square inch) is applied to dirty or heavily contaminated wounds [3, 12]. Additionally, mechanical cleaning with high-pressure irrigation may effectively decrease the level of bacterial contamination and reduce the incidence of wound infection $[4,13]$.

\section{Negative-pressure wound therapy (NPWT)}

NPWT systems (also referred to as vacuum-assisted wound closure) are composed of an open-pore sponge, semi-occlusive dressing, and negative pressure source and are commonly available in the US [10,14]. Negative pressure ranging from -50 to $-200 \mathrm{mmHg}$ may be effective in higher-risk infective wounds [15]. NPWT has the frequently cited advantage of bacteria clearance from the wound environment. It was shown to reduce the bacterial bio-burden in wounds in the animal open fracture model contaminated with gram-negative bacilli. The colonization of gram-positive cocci (e.g., Staphylococcus aureus) also exists [16]. In addition, NPWT has more benefits than dressings do in the setting of wound infection [15-17]. Patients with persistent drainage treated with NPWT for at least 5 days had a lower rate of wound infection and a shorter period of drainage than did patients in the compressive dressing group [15]. Several studies have shown that the wound infection rate in the patients who adopted NPWT was significantly lower than that in patients in the wet-to-dry (WTD) group $[16,17]$. In military fields, using NPWT during intercontinental aeromedical evacuation of combat casualties may also provide many benefits, such as earlier wound closure, lower infection rates, and better pain management $[8,18]$.

\section{Wound drainage}

Thorough wound drainage following debridement and irrigation is one of the steps in the basic principles of the management of combat-related injuries [3]. Traditional drains are commonly used within $24 \mathrm{~h}$ in wounds with deep cavities and dead space. Stannard et al. [15] evaluated the efficiency of NPWT for the management of persistent wound drainage. In addition, Rispoli et al. [19] reported a new technique, combining NPWT with traditional drainage, that allowed the conversion of deep cavitary defects to superficial defects to facilitate drainage. Further, deep wound infection was better controlled, and there were no complications detected such as abscess formation, tube-associated skin necrosis, or sepsis.

\section{Wound dressings}

A bulky absorbent dressing or cotton wool is necessary for an adequately excised wound. Bandaging wounds with sterile dressings is commonly used in initial care on the battlefield. Silver nitrate solution is routinely applied to dressings following burns [3, 8]. WTD dressings were suggested to be the standard of method for soft-tissue 
defects and open wounds in the past. Because WTD is associated with increased patient pain, healthcare costs and risk of nosocomial infections, safe and effective wound dressings are required [10]. Guthrie et al. [20] compared 3 dressings, Inadine ${ }^{\oplus}$ (USA), Acticoat ${ }^{\circ}$ (Hull, UK) and Activon Tulle (Nottingham, UK) in a rabbit model of contaminated forelimb muscle injury. They found that the Inadine and Acticoat groups had significantly lower bacterial counts.

\section{Wound closure}

It is important that the wound be closed as soon as doing so is safe, but not before and not long thereafter $[3,21]$. Traumatic laceration wounds $(\leq 5 \mathrm{~cm})$ without signs of infection can be closed immediately, and disinfected wounds may be closed up to $24 \mathrm{~h}$ afterwards (based on the Friedrich dogma); wounds with active signs of infection should undergo secondary closure after 3-5 days [22]. There is no powerful evidence to demonstrate that traumatic wounds should not be sutured after 6 hours. Baar et al. [23] conducted a prospective cohort study and showed that the duration of the wound (older or younger than 6 hours) was not a critical factor in the decision of wound closure. Contaminated wounds should never be primarily closed. Delayed primary closure (DPC) appears necessary to treat severely contaminated or macerated wounds after multiple debridement and irrigation procedures $[9,21]$.

\section{Pharmaceuticals}

The most common effective intervention other than surgical management after trauma is the use of pharmaceuticals. Antibiotics are now generally recommended for wound and nosocomial infection prevention. In addition, tetanus vaccination, chlorhexidine, hydrocortisone, detrusor botulinum toxin A (BoNTA) injection, immunoglobulin, IFN- $\gamma$, and glucan have been noted in several studies and play an active role in preventing traumarelated infection.

\section{Prophylactic antibiotics}

According to the International Committee of the Red Cross (ICRC) Antibiotic protocol, the proper use of antibiotics is based on different types of injury [3]. Additionally, the US guidelines for the use of antibiotics in combat-related injuries suggest that post-traumatic antimicrobial agent selection and duration should be based on different combat-related injury patterns. For instance, antibiotic treatment for the following should be considered: extremity wounds (cefazolin, 2 g IV q6-8 h, 1-3 days), thoracic wounds (cefazolin, 2 g IV q6-8 h, 1 day after washout; if penetrating chest injury with esophageal disruption, metronidazole $500 \mathrm{mg}$ IV q8-12 h is added), abdominal wounds (cefazolin $2 \mathrm{~g}$ IV $\mathrm{q6}-8 \mathrm{~h}$ with metronidazole $500 \mathrm{mg}$ IV q8-12 h, 1 day after washout), maxillofacial and neck wounds (cefazolin, 2 g IV q6-8 h, 1 day), central nervous system wounds (cefazolin, $2 \mathrm{~g}$ IV q6-8 h, 5 days or until CSF; if contamination and abdominal cavity are involved, metronidazole $500 \mathrm{mg}$ IV q8-12 $\mathrm{h}$ is added), and penetrating eye wounds (levofloxacin, $500 \mathrm{mg}$ IV/PO once a day, 7 days) [8].

Many exploratory studies are drawing wide concern for the use of prophylactic antibiotics after trauma. Here, we list the basic principles.

- The time of administration Because the amount of bacteria increases exponentially from the time of trauma, $6 \mathrm{~h}$ appears to be a vital period after wound contamination. It is necessary to extend the time of antibiotic treatment if an unavoidable delay exists in administering antibiotics when the wound is open [4]. The ICRC suggests that penicillin, if it is not administered within $6 \mathrm{~h}$ in pre-hospital uncomplicated soft-tissue Grade 1 wounds, actually increases the risk of infection, which may be unavoidable [3].

- The choice of antibiotics Immediate treatment with broad-spectrum intravenous antibiotics based on the Gustilo and Anderson classification should be given in patients with open fractures or extensive soft tissue loss [11, 24]. High-dose intravenous 3rd-generation cephalosporins, rather than oral 1st-generation drugs, may be effective in patients with open fractures [25]. The incidence of wound infection in patients with fresh traumatic wounds or lacerations is low after the administration of co-amoxiclav [22, 26]. Cefazolin, or vancomycin if the patient is allergic to penicillin, cefoxitin/clindamycin and gentamicin, or clindamycin and gentamicin are commonly administered to patients in the trauma intensive care unit (TICU) [27].

- The course/dose of antibiotics Both civilian and military studies suggest that a short course and single dose of cephalosporins are important to prevent wound infection in open fractures and should be administered for either 3 days after injury or $24 \mathrm{~h}$ after wound closure [28]. Patients with penetrating abdominal trauma and concomitant thoracolumbar or sacral (TLS) fracture receiving prophylactic antibiotics for $\leq 48$ hours do not develop spinal infections [29]. Prophylactic antibiotic research is applicable not only at the site of trauma wound infection but also in patients with nosocomial infections (early VAP and Clostridium difficile infection) [30, 31].

- The route of antibiotic administration There are several routes of antibiotics administration, depending on the different types of trauma. The administration of oral antibiotics is often applied to prevent wound infection for simple traumatic 
wounds [32, 33]. In addition, antibiotic ointments containing bacitracin, polymyxin, neomycin or cetrimide are often used in minor uncomplicated soft tissue wounds and have lower skin infection rates [34].

Overall, the recent studies concentrated on the prophylactic antibiotics after trauma are mostly retrospective and include the integration of expert opinions, but significant, random, double-blind, prospective studies are lacking.

\section{Tetanus vaccination}

The incubation period of tetanus is 3 to 21 days, and the risk of developing tetanus is great in any penetrating wound infection, especially in deep, small, punctate wounds. It is crucial for all trauma patients with deep wounds to receive appropriate immunization against tetanus. The present tetanus vaccination requirement, as a booster or revaccination, should also be considered by clinicians according to local protocols [22]. Because emergency clinicians are frequently faced with patients who are sensitive to tetanus infection in the emergency department, the attitude toward tetanus prophylaxis should be changed among emergency physicians [35].

\section{Chlorhexidine (CHX)}

For incontinence care, the involved skin should be wiped with as many chlorhexidine cloths as necessary after routine cleaning with soap and water. Chlorhexidine has been shown to be useful in reducing Acinetobacter colonization of the skin of ICU patients [8]. However, the effect of chlorhexidine on preventing nosocomial infection in trauma patients is controversial. Critically injured patients receiving daily bathing with $2 \%$ chlorhexidine exhibited lower rates of catheter-related bloodstream infection and methicillin-resistant Staphylococcus aureus (MRSA) VAP [36]. Receiving chlorhexidine both from the time of admission to 48 and $72 \mathrm{~h}$ is also effective [37]. However, the administration of oral chlorhexidine over the first $48 \mathrm{~h}$ could not minimize the risk of VAP for intubated trauma patients [38].

\section{Hydrocortisone}

Adrenal insufficiency that alters organism immunity often occurs in severe trauma patients. Administration of an intravenous stress-dose of hydrocortisone has been associated with a lower incidence of hospital-acquired pneumonia (HAP) in ventilated patients with trauma $[39,40]$. Subsequently, researchers have described the mechanism of hydrocortisone in a post-traumatic pneumonia mouse model; hydrocortisone can decrease trauma-induced immunosuppression by modulating the communication between DC and NK cells [41].

\section{Other interventions}

The most common clinical complication in patients with an indwelling catheter after spinal cord injury (SCI) is UTI. Neurogenic detrusor overactivity (NDO) is frequently detected in SCI patients and increases the risk of UTI. BoNTA injection may significantly reduce UTI in SCI patients with NDO and appears to decrease detrusor pressure [42]. In addition, immunomodulatory interventions such as immunoglobulin, IFN- $\gamma$, or glucan are the most effective in improving infection and MOF in trauma patients [43].

\section{Enteral nutrition (EN)}

Receiving EN within 24 hours of severe injury and/or ICU admission can significantly reduce the pneumonia rate [44]. Some studies have indicated that both the nutritional quality and type of EN are critical for reducing hospital-acquired infections following trauma. Highquality EN formulas that contain omega-3 fats, extra levels of vitamins, minerals, and amino acids (such as glutamine) have been shown to reduce the rates of nosocomial pneumonia, bacteremia, abdominal abscesses, and UTI compared to standard EN [45]. The use of EN containing fish oil but not arginine is associated with a lower risk of secondary nosocomial infection [46]. EN with added probiotics is associated with a lower incidence of VAP [47]. In addition, transpyloric feeding (TPF) is associated with lower rates of VAP in severe TBI patients compared to gastric feeding (GF) [48].

\section{Management of the tube system}

Practitioners placing central venous catheters in severe trauma patients should strictly observe sterile techniques to reduce the incidence of central line-associated blood stream infections (CLBSIs) [49]. Choosing the proper tube type is as critical as the indwelling time on intubation in trauma patients. Traumatic hemothorax with central venous catheter (CVC) placement has been associated with a lower infection rate of surgical wounds than a conventional large-bore chest tube [50]. Reducing the time of the indwelling urinary catheter could reduce the rate of UTI [51, 52].

\section{Organ dysfunction (OD) prevention}

OD prevention has received increasing attention in patients with serious infections. Treatment with the calcium channel sensitizer levosimendan has been shown to be potentially advantageous for organ function in severe sepsis, especially on myocardial function [53-57]. Cardiopulmonary bypass (CPB), which is an essential cardiac surgery technique, appears to alleviate inflammation and prevent OD [58]. Critically ill patients who have an increased risk of extensive endothelial damage receiving autologous transplantation of endothelial progenitor cells (EPCs) may experience a restoration in blood flow, 
which could improve the function of important organs and thereby prevent MODS [59]. In addition, the Chinese medicine therapy of clearing-heat and detoxifying has also demonstrated beneficial effects on MODS prevention [60]. The effect of remote ischemic preconditioning (RIPC), which is a strategy to reduce ischemia in remote organs, has been controversial in renal injury [61]. Although the above pharmaceuticals and medical strategies have shown potentially preventive effects on OD, these measures have not yet been evaluated for use on trauma patients.

Some studies have reported several major risk factors in trauma patients leading to MODS, e.g., older age, the presence of chronic diseases, hypo-perfusion, infection, and immuno-depression [62-65]. To date, few effective interventions have been applied in OD prevention following trauma.

\section{Pharmaceuticals}

Immunoglobulin, IFN- $\gamma$, or glucan may be effective in improving MOF in trauma patients [45]. Obese trauma patients $\left(B M I>30 \mathrm{~kg} / \mathrm{m}^{2}\right)$ with an increased risk of MOF who received pre-injury angiotensin-converting enzyme inhibitor/angiotensin (ACE/ARB) therapy have markedly higher Marshall and Denver-2 scores compared to patients who did not receive these medications $[66,67]$. Patients receiving either $7.5 \%$ hypertonic saline (HS) or $7.5 \%$ HS with $6 \%$ dextran-70 (HSD) have a lower incidence of MODS than do patients receiving $0.9 \%$ normal saline (NS) [68].

\section{Healthcare strategy}

Patients with vascular injuries (arterial/ venous) at a Civilian Level I Trauma Center undergoing temporary intravascular shunt (TIVS) placement have lower rates of MOF and sepsis [69]. MOF appears to be prevented in critical multiple trauma patients on mechanical ventilation by using lung-protective strategies, avoiding high volumes and inspiratory pressure and improving the proportion of aerated lung during expiration. It has been shown that the rates of single organ failure, two organ failure and MOF are low [70]. The administration of a high-quality EN is important in trauma patients to prevent a nosocomial infection such as VAP or UTI [44-48]. The immunonutrition of EN and immuneenhancing diet also have demonstrated a vital role in reducing MOF following severe trauma. A combination of arginine, $\mathrm{n}$-3-fatty acids and nucleotides has been associated with lower septic complications and lower MOF scores [71]. In addition, Chinese traditional treatment has potential validity in the prevention of OD. Acupuncture, which uses special thin needles that are pushed into the skin at particular points on the body, can activate vagal activity and cholinergic anti-inflammatory pathways and thereby improve the outcome of multiple traumatic patients. Liang et al. [72] reported that acupuncture at the ST-36 and PC-6 acupoints was associated with a lower incidence of systemic inflammatory response syndrome (SIRS), ARDS, sepsis and MOF.

\section{Conclusions}

The initial intervention for sepsis following trauma is still a challenge. Early prevention for trauma patients can improve outcome and decrease mortality. Although many research studies about infection prevention in trauma patients have been published, there is a lack of guidelines for antibiotics after trauma, and some of the results are controversial. Currently, few effective interventions are applicable in the prevention of OD following trauma. Trauma can affect immunologic function, and wound infection, nosocomial infection, and secondary OD are all risk factors that are associated with sepsis following trauma. A new combination of measures can be generated to improve post-traumatic outcome. Overall, more efficient ways to prevent trauma-related infection and sepsis should be developed.

\section{Abbreviations \\ ACE/ARB: Angiotensin-converting enzyme inhibitor/angiotensin receptor blocker; ARDS: Acute respiratory distress syndrome; BoNTA: Botulinum toxin A; CHX: Chlorhexidine; CLBSIs: Central line-associated blood stream infections; CMA: Chinese Medical Association; CPB: Cardiopulmonary Bypass; CVC: Central venous catheter; DPC: Delayed primary closure; EN: Enteral nutrition; EPCs: Endothelial progenitor cells; GF: Gastric feeding; HAP: Hospital-acquired pneumonia; HS: Hypertonic saline; HSD: Hypertonic saline dextran; ICRC: International Committee of the Red Cross; MODS: Multiple organ dysfunction syndrome; MOF: Multiple organ failure; MRSA: Methicillin-resistant Staphylococcus aureus; NDO: Neurogenic detrusor overactivity; NPWT: Negative-pressure wound therapy; NS: Normal saline; OD: Organ dysfunction; RIPC: Remote ischemic preconditioning; SCI: Spinal cord injury; SIRS: Systemic inflammatory response syndrome; \\ SOFA: Sequential Organ Failure Assessment; TICU: Trauma intensive care unit; TIVS: Temporary intravascular shunts; TLS: Thoracolumbar or sacral; TPF: Transpyloric feeding; UTI: Urinary tract infection; VAP: Ventilator associated pneumonia; WTD: Wet-to-dry}

\section{Acknowledgement}

This study was supported by grants from the National Basic Research Program of China (973 Program) (No. 2012CB518102), the key project of "Twelfth Five-Year" plan for medical science and technology of PLA (No. BWS11J038), and the special fund from PLA (2014ZX09J14107-08C). All funding bodies played an important role in the design of the study and data collection, and in the writing of the manuscript.

\section{Funding}

None.

Availability of data and materials

There are no reproducible data in this article.

\section{Authors' contributions}

XYM participated in the collection and collation of literature and drafted the manuscript. LXT participated in the collection and collation of literature. HPL instructed the writing of this manuscript. All authors read and approved the final manuscript.

Competing interests

The authors declare that they have no competing interests. 


\section{Consent for publication}

Not applicable.

\section{Ethics approval and consent to participate}

Not applicable.

Received: 18 February 2016 Accepted: 20 October 2016

Published online: 08 November 2016

\section{References}

1. Morrison JJ, Yapp LZ, Beattie A, Devlin E, Samarage M, McCaffer C, et al. The epidemiology of Scottish trauma: A comparison of pre-hospital and inhospital deaths, 2000 to 2011. Surgeon. 2016;14(1):1-6.

2. Binkowska AM, Michalak G, Slotwinski R. Current views on the mechanisms of immune responses to trauma and infection. Cent Eur J Immunol. 2015; 40(2):206-16.

3. Giannou C, Baldan M. War Surgery: Working with limited resources in armed conflict and other situations of violence, vol. 1. Geneva: ICRC; 2010;1:253-266

4. Edlich RF, Rodeheaver GT, Thacker JG, Lin KY, Drake DB, Mason SS, et al. Revolutionary advances in the management of traumatic wounds in the emergency department during the last 40 years: part II. J Emerg Med. 2010; 38(2):201-7

5. Masterson TM, Rodeheaver GT, Morgan RF, Edlich RF. Bacteriologic evaluation of electric clippers for surgical hair removal. Am J Surg. 1984; 148(3):301-2.

6. Mangram AJ, Horan TC, Pearson ML, Silver LC, Jarvis WR. Guideline for prevention of surgical site infection, 1999. Centers for Disease Control and Prevention (CDC) Hospital Infection Control Practices Advisory Committee. Am J Infect Control. 1999;27(2):97-132.

7. Custer J, Edlich RF, Prusak M, Madden J, Panek P, Wangensteen OH. Studies in the management of the contaminated wound. $V$. Anassessment of the effectiveness of pHisoHex and Betadine surgical scrub solutions. Am J Surg. 1971;121(5):572-5.

8. Hospenthal DR, Murray CK, Andersen RC, Bell RB, Calhoun JH, Cancio LC, et al. Guidelines for the prevention of infections associated with combatrelated injuries: 2011 update: endorsed by the Infectious Diseases Society of America and the Surgical Infection Society. J Trauma. 2011;71(2 Suppl 2): S210-34.

9. Ray JM. The treatment of maxillofacial trauma in austere conditions. Atlas Oral Maxillofac Surg Clin North Am. 2013;21(1):9-14.

10. Streubel PN, Stinner DJ, Obremskey WT. Use of negative-pressure wound therapy in orthopaedic trauma. J Am Acad Orthop Surg. 2012;20(9):564-74.

11. Ferreira J, Fowler JR. Management of complications relating to complex traumatic hand injuries. Hand Clin. 2015;31(2):311-7.

12. Stevenson TR, Thacker JG, Rodeheaver GT, Bacchetta C, Edgerton MT, Edlich RF. Cleansing the traumatic wound by high-pressure syringe irrigation. JACEP. 1976:5:17-21.

13. Leslie LF, Faulkner BC, Woods JA, Hill RA, Thacker JG, Rodeheaver GT, et al. Wound cleansing by irrigation for implant surgery. J Long Term Eff Med Implants. 1995;5(2):111-28.

14. Weinlein J, Schmidt AH. What's new in orthopaedic trauma. J Bone Joint Surg Am. 2010;92(12):2247-60.

15. Stannard JP, Robinson JT, Anderson ER, McGwin Jr G, Volgas DA, Alonso JE. Negative pressure wound therapy to treat hematomas and surgical incisions following high-energy trauma. J Trauma. 2006;60(6):1301-6.

16. Lalliss SJ, Stinner DJ, Waterman SM, Branstetter JG, Masini BD, Wenke JC. Negative pressure wound therapy reduces pseudomonas wound contamination more than Staphylococcus aureus. J Orthop Trauma. 2010; 24(9):598-602.

17. Stannard JP, Volgas DA, Stewart R, McGwin Jr G, Alonso JE. Negative pressure wound therapy after severe open fractures: A prospective randomized study. J Orthop Trauma. 2009;23(8):552-7.

18. Fang R, Dorlac WC, Flaherty SF, Tuman C, Cain SM, Popey TL, et al. Feasibility of negative pressure wound therapy during intercontinental aeromedical evacuation of combat casualties [J]. J Trauma. 2010;69 Suppl 1: S140-5.

19. Rispoli DM, Horne BR, Kryzak TJ, Richardson MW. Description of a technique for vacuum-assisted deep drains in the management of cavitary defects and deep infections in devastating military and civilian trauma. J Trauma. 2010; 68(5):1247-52
20. Guthrie HC, Martin KR, Taylor C, Spear AM, Whiting R, Macildowie S, et al. A pre-clinical evaluation of silver, iodine and Manuka honey based dressings in a model of traumatic extremity wounds contaminated with Staphylococcus aureus. Injury. 2014:45(8):1171-8.

21. Shanahan DR. Inaugural professorial lecture: the progression of trauma wound care. Why delay wound closure? J Wound Care. 2013;22(4):194-6.

22. Duane TM, Young A, Weber W, Wolfe LG, Malhotra AK, Aboutanos MB, et al. Bladder pressure measurements and urinary tract infection in trauma patients. Surg Infect (Larchmt). 2012;13(2):85-7.

23. van den Baar MT, van der Palen J, Vroon MI, Bertelink P, Hendrix R. Is time to closure a factor in the occurrence of infection in traumatic wounds? A prospective cohort study in a Dutch level 1 trauma centre. Emerg Med J. 2010:27(7):540-3.

24. Hake ME, Young H, Hak DJ, Stahel PF, Hammerberg EM, Mauffrey C. Local antibiotic therapy strategies in orthopaedic trauma: Practical tips and tricks and review of the literature. Injury. 2015;46(8):1447-56.

25. Barton CA, McMillian WD, Crookes BA, Osler T, Bartlett 3rd CS. Compliance with the Eastern Association for the Surgery of Trauma guidelines for prophylactic antibiotics after open extremity fracture. Int J Crit IIIn Inj Sci. 2012;2(2):57-62.

26. Sirijatuphat R, Siritongtaworn P, Sripojtham V, Boonyasiri A, Thamlikitkul V. Bacterial contamination of fresh traumatic wounds at Trauma Center, Siriraj Hospital, Bangkok, Thailand. J Med Assoc Thai. 2014;97 Suppl 3:S20-5.

27. Dortch MJ, Fleming SB, Kauffmann RM, Dossett LA, Talbot TR, May AK. Infection reduction strategies including antibiotic stewardship protocols in surgical and trauma intensive care units are associated with reduced resistant gram-negative healthcare-associated infections. Surg Infect (Larchmt). 2011;12(1):15-25.

28. Hoff WS, Bonadies JA, Cachecho R, Dorlac WC. East Practice Management Guidelines Work Group: update to practice management guidelines for prophylactic antibiotic use in open fractures. J Trauma Acute Care Surg. 2011;70(3):751-4.

29. Pasupuleti LV, Sifri ZC, Mohr AM. Is extended antibiotic prophylaxis necessary after penetrating trauma to the thoracolumbar spine with concomitant intraperitoneal injuries? Surg Infect (Larchmt). 2014;15(1):8-13.

30. Poole D, Chieregato A, Langer M, Viaggi B, Cingolani E, Malacarne $\mathrm{P}$, et al. Systematic review of the literature and evidence-based recommendations for antibiotic prophylaxis in trauma: results from an Italian consensus of experts. PLoS One. 2014;9(11):e113676.

31. Shah K, Pass LA, Cox M, Lanham M, Arnold FW. Evaluating contemporary antibiotics as a risk factor for Clostridium difficile infection in surgical trauma patients. J Trauma Acute Care Surg. 2012;72(3):691-5.

32. Erbil B, Ersoy G, Özkütük A, Akarca FK, Korkmaz T, Demir ÖF, et al. The effects of oral antibiotics on infection prophylaxis in traumatic wounds. Ulus Travma Acil Cerrahi Derg. 2014;20(4):231-5.

33. Cowell DL, Harvey M, Cave G. Antibiotic prophylaxis at triage for simple traumatic wounds: a pilot study. Eur J Emerg Med. 2011;18(5):279-81.

34. Waterbrook AL, Hiller K, Hays DP, Berkman M. Do topical antibiotics help prevent infection in minor traumatic uncomplicated soft tissue wounds? Ann Emerg Med. 2013;61(1):86-8.

35. Yoon YH, Moon SW, Choi SH, Cho YD, Kim JY, Kwak YH. Clinician awareness of tetanus-diphtheria vaccination in trauma patients: a questionnaire study. Scand J Trauma Resusc Emerg Med. 2012;20:35.

36. Evans $H L$, Dellit TH, Chan J, Nathens AB, Maier RV, Cuschieri J. Effect of chlorhexidine whole-body bathing on hospital-acquired infections among trauma patients. Arch Surg. 2010;145(3):240-6.

37. Grap MJ, Munro CL, Hamilton VA, Elswick Jr RK, Sessler CN, Ward KR. Early, single chlorhexidine application reduces ventilator-associated pneumonia in trauma patients. Heart Lung. 2011;40(5):e115-22.

38. Mohr NM, Pelaez Gil CA, Harland KK, Faine B, Stoltze A, Pearson K, et al. Prehospital oral chlorhexidine does not reduce the rate of ventilatorassociated pneumonia among critically ill trauma patients: A prospective concurrent-control study. J Crit Care. 2015;30(4):787-92.

39. Kwon YS, Suh GY, Jeon K, Park SY, Lim SY, Koh WJ, et al. Serum cytokines and critical illness-related corticosteroid insufficiency. Intensive Care Med. 2010;36(11):1845-51

40. Roquilly A, Mahe PJ, Seguin P, Guitton C, Floch H, Tellier AC, et al. Hydrocortisone therapy for patients with multiple trauma: the randomized controlled HYPOLYTE study. JAMA. 2011;305(12):1201-9.

41. Roquilly A, Broquet A, Jacqueline C, Masson D, Segain JP, Braudeau C, et al. Hydrocortisone prevents immunosuppression by interleukin-10+ natural killer cells after trauma-hemorrhage. Crit Care Med. 2014;42(12):e752-61. 
42. Jia C, Liao LM, Chen G, Sui Y. Detrusor botulinum toxin A injection significantly decreased urinary tract infection in patients with traumatic spinal cord injury. Spinal Cord. 2013;51(6):487-90.

43. Spruijt NE, Visser T, Leenen LP. A systematic review of randomized controlled trials exploring the effect of immunomodulative interventions on infection, organ failure, and mortality in trauma patients. Crit Care. 2010; 14(4):R150.

44. Curtis L. Early, high quality enteral nutrition significantly improves outcome in head trauma patients. J Neurotrauma. 2011;28(10):2197-8.

45. Montejo JC, Zarazaga A, López-Martínez J, Urrútia G, Roqué M, Blesa AL, et al. Immunonutrition in the intensive care unit. A systematic review and consensus statement. Clin Nutr. 2003;22(3):221-3.

46. Marik PE, Zaloga GP. Immunonutrition in critically ill patients: a systematic review and analysis of the literature. Intensive Care Med. 2008;34(11):1980-90.

47. Gu WJ, Deng T, Gong YZ, Jing R, Liu JC. The effects of probiotics in early enteral nutrition on the outcomes of trauma: a meta-analysis of randomized controlled trials. JPEN J Parenter Enteral Nutr. 2013;37(3):310-7.

48. Acosta-Escribano J, Fernández-Vivas M, Grau Carmona T, Caturla-Such J, Garcia-Martinez M, Menendez-Mainer A, et al. Gastric versus transpyloric feeding in severe traumatic brain injury: a prospective, randomized trial. Intensive Care Med. 2010;36(9):1532-9.

49. Smith JW, Egger M, Franklin G, Harbrecht B, Richardson JD. Central lineassociated blood stream infection in the critically ill trauma patient. Am Surg. 2011;77(8):1038-42

50. Yi JH, Liu HB, Zhang M, Wu JS, Yang JX, Chen JM, et al. Management of traumatic hemothorax by closed thoracic drainage using a central venous catheter. J Zhejiang Univ Sci B. 2012;13(1):43-8.

51. Chua C, Wisniewski T, Ramos A, Schlepp M, Fildes JJ, Kuhls DA. Multidisciplinary trauma intensive care unit checklist: Impact on infection rates. J Trauma Nurs. 2010;17(3):163-6.

52. Elpern EH, Killeen K, Ketchem A, Wiley A, Patel G, Lateef O. Reducing use of indwelling urinary catheters and associated urinary tract infections. Am J Crit Care. 2009;18(6):535-41.

53. Orme RM, Perkins GD, McAuley DF, Liu KD, Mason AJ, Morelli A, et al. An efficacy and mechanism evaluation study of Levosimendan for the Prevention of Acute oRgan Dysfunction in Sepsis (LeoPARDS): protocol for a randomized controlled trial. Trials. 2014;15:199

54. Morelli A, Donati A, Ertmer C, Rehberg S, Lange M, Orecchioni A, et al. Levosimendan for resuscitating the microcirculation in patients with septic shock: a randomized controlled study. Crit Care. 2010;14(6):R232.

55. Alhashemi JA, Alotaibi QA, Abdullah GM, Shalabi SA. Levosimendan vs dobutamine in septic shock. J Crit Care. 2009;24(3):e14-5.

56. Vaitsis J, Michalopoulou H, Thomopoulos C, Massias S, Stamatis P. Use of levosimendan in myocardial dysfunction due to sepsis. Crit Care. 2009;13 Suppl 1:165

57. Memis D, Inal MT, Sut N. The effects of levosimendan vs dobutamine added to dopamine on liver functions assessed with noninvasive liver function monitoring in patients with septic shock. J Crit Care. 2012;27(318):e311-6.

58. Esper SA, Subramaniam K, Tanaka KA. Pathophysiology of Cardiopulmonary bypass: current strategies for the prevention and treatment of anemia, coagulopathy, and organ dysfunction. Semin Cardiothorac Vasc Anesth. 2014;18(2):161-76.

59. Tianhang L, Bo W, Zhengmao L, Tao P, Hong Z, Xuchao X, et al. Autologous transplantation of endothelial progenitor cells to prevent multiple organ dysfunction syndromes in pig. J Trauma Acute Care Surg. 2013;74(2):508-15.

60. He JZ, Zhang MZ, Wang L. Progress on study of inflammatory reaction in multi-organ dysfunction syndrome prevention and treatment by Chinese medicine therapy of clearing-heat and detoxifying. Zhongguo Zhong Xi Yi Jie He Za Zhi. 2010;30(8):797-801.

61. Macedo E, Mehta RL. Renal injury: Preventing organ dysfunction-is preconditioning still an option? Nat Rev Nephrol. 2016;12(1):8-9.

62. Baldwin KM, Morris SE. Shock, multiple organ dysfunction syndrome, and burns in adults. In: McCance KL, Huether SE, editors. Pathophysiology: The biological basis for disease in adults and children. 4th ed. Philadelphia: WB Saunders; 2002. p. 1483-512.

63. Ferri FF. Infectious diseases. In: Ferri FF, editor. Practical guide to the care of the medical patient. 6th ed. St. Louis: Mosby; 2004. p. 519-666.

64. Parillo JE. Approach to the patient in shock. In: Goldman L, Ausiello D, editors. Cecil: Textbook of medicine. 22nd ed. Philadelphia: WB Saunders; 2004. p. 608-15.

65. Walsh CR. Multiple organ dysfunction syndrome after multiple trauma Orthop Nurs. 2005;24(5):324-3.
66. Winfield RD, Bochicchio GV. The critically injured obese patient: a review and a look ahead. J Am Coll Surg. 2013;216(6):1193-206.

67. Winfield RD, Southard RE, Turnbull IR, Bochicchio K, Reese S, Freeman BD, et al. Angiotensin inhibition is associated with preservation of t-cell and monocyte function and decreases multiple organ failure in obese trauma patients. J Am Coll Surg. 2015;221(2):486-94.

68. Junger WG, Rhind SG, Rizoli SB, Cuschieri J, Shiu MY, Baker AJ, et al. Resuscitation of traumatic hemorrhagic shock patients with hypertonic saline-without dextran-inhibits neutrophil and endothelial cell activation. Shock. 2012;38(4):341-50.

69. Subramanian A, Vercruysse G, Dente C, Wyrzykowski A, King E, Feliciano DV A decade's experience with temporary intravascular shunts at a civilian level I trauma center. J Trauma. 2008;65(2):316-24.

70. Laudi S, Donaubauer B, Busch T, Kerner T, Bercker S, Bail H, et al. Low incidence of multiple organ failure after major trauma. Injury. 2007;38(9): 1052-8.

71. Bastian L, Weimann A. Immunonutrition in patients after multiple trauma. $\mathrm{Br}$ I Nutr. 2002:87 Suppl 1:S133-4.

72. Liang $\mathrm{H}, \mathrm{Qu}$ J. Decreased incidence of SIRS and sepsis by acupuncture in severe multiple traumatic patients via facilitation of vagal activity. Crit Care. 2012;16 Suppl 3:38.

\section{Submit your next manuscript to BioMed Central and we will help you at every step:}

- We accept pre-submission inquiries

- Our selector tool helps you to find the most relevant journal

- We provide round the clock customer support

- Convenient online submission

- Thorough peer review

- Inclusion in PubMed and all major indexing services

- Maximum visibility for your research

Submit your manuscript at www.biomedcentral.com/submit
) Biomed Central 